\title{
Burnout Syndrome Among Nursing Staff: Performing Data Analysis using the SPSS Statistic
}

\author{
https://doi.org/10.3991/ijoe.v17i04.20979 \\ Mohammed Amine Lafraxo $(\varpi)$ \\ Ibn Tofail University, Kenitra, Morocco \\ lafraxo.ma@gmail.com \\ Mohammed Ouadoud \\ Abdelmalek Essaadi University, Tetouan, Morocco \\ Youssef El Madhi \\ Regional Center for Education and Training Trades, Rabat, Morocco \\ Abdelmajid Soulaymani \\ Ibn Tofail University, Kenitra, Morocco
}

\begin{abstract}
This study aimed to evaluate the prevalence of burnout among nurses, to determine the socio-demographic characteristics associated with burnout, and to assess the influence of the practice of physical activities on burnout. This is an observational study of a cross-sectional type. A selfadministered survey was used to determine the professional and sociodemographic characteristics. The Ricci-Gagnon questionnaire to assess the level of physical activity and sports practice and the Copenhagen Burnout Inventory to evaluate burnout. In total, $16.7 \%$ of the participating nurses displayed a high level of general burnout (63.3\% medium, 20\% low), and 23\% displayed a high level of patient-related burnout (34\% medium, $43 \%$ low). Physical activity had no protective effect against burnout, as $87 \%$ of participants were physically active. This research result confirmed what exists in other scientific publications; the prevalence of burnout is a reality in the health professions. It is necessary to think of setting up accompaniments to sensitize nurses for primary prevention against burnout.
\end{abstract}

Keywords - Burnout, Copenhagen burnout inventory, physical activity, information technology, data analysis, SPSS Statistic

\section{$1 \quad$ Introduction}

Occupational health is a process that aims to create a healthier workplace, it has an essential role in the development of nations and societies, it is crucial to improving workers' health in the face of different demographic, social, and economic challenges [1]. The French National Authority for Health (HAS) states that active healthcare professionals are increasingly susceptible to burnout [2]. Burnout is defined as a syn- 
drome involving emotional, physical, and mental exhaustion stemming from work situations that are emotionally demanding [3]. According to the biological model, Cannon has defined burnout as a neuro-vegetative response to external attacks that change the normal physiological state and bring about a disruption of homeostasis [4], in other words, it is the biological response of the human organism to a threatening situation. It is known to be responsible for the appearance of several mental, somatic and behavioral conditions, such as digestive, cardiovascular, and musculoskeletal risks, or even conflict situations and isolation [5].

There is a high prevalence of burnout in the nursing profession. It is a profession in which social interactions are frequent [6], and where the role requires appreciable commitment and lots of sacrifices [7].

This study aimed to evaluate the prevalence of burnout among nurses, to determine the socio-demographic characteristics associated with burnout, and to assess the influence of the practice of physical activities on burnout.

This article consists of four main sections:

- In the first section, we present the research methodology adopted to evaluate burnout using "CBI", and the practice of physical activities and sports using "Ricci-Gagnon questionnaire".

- In the second section, we reveal the results of the survey. The data processing was carried out with the SPSS tool.

- In the third section, we tried to compare the results found with results from other studies.

- In section four, we will describe the future project that will be based on the results of this study, which is the implementation of a mobile health information system for the prevention of burnout.

\section{Methods}

\subsection{Participants}

This is an observational study of a cross-sectional type [8], carried out among nurses at the Mohammed VI University Hospital (Hassan II Oncology Centre) in Oujda - Morocco - with a response rate of $100 \%$ among those included. Recruits, nurses on leave, and nurses performing administrative tasks were excluded from the study.

\subsection{Data collection}

The data collected with the help of a self-administered questionnaire made up of three sections: 
- The sociodemographic, professional, and personal characteristics (gender, age, marital status, specialty, years of experience, diet, food supplements, sport).

- The Ricci-Gagnon questionnaire [9] was used to evaluate the level of physical activity and sports practice. It consists of three parts, the first is to determine the intensity of sedentary behavior (TV, computer, work, etc.); the second is to evaluate the duration of leisure-time physical and sports activity (sport); the third is to assess daily physical activity (walking, housework, gardening, etc.). The result of the questionnaire is a score classified as inactive if the total score is less than 18; active between 18 and 35; very active if the total score is greater than 35 .

- Burnout was measured using a score according to the Copenhagen Burnout Inventory - CBI [5], [10]-[12]. This is a validated instrument for measuring burnout and has been used in lots of scientific research studies, specifically in studies and research carried out among healthcare professionals. The Copenhagen Burnout Inventory result is a score expressed as low: 1 to 2.4; medium: 2.5 to 3.5; or high: 3.6 to 5, which allows the two, levels of burnout to be assessed. The validated French version examines 12 items, which ascertain two dimensions: The general burnout score is the first dimension, it is the extent to which a sense of burnout is experienced, it is defined as the extent of intense fatigue and physical and psychological exhaustion experienced by the individual. Patientrelated burnout is the second dimension measures the extent to which the sense of burnout is linked to the work of caring for patients. This is the result of physical and psychological exhaustion perceived by the individual as being linked to working with others [13] [14].

\subsection{Statistical analysis}

The result of the Copenhagen Burnout Inventory and The Ricci-Gagnon questionnaire was verified and processed using IPM-SPSS 23 software. The Fisher Exact Test has been used to identify any associations between the sociodemographic, personal, and professional characteristics and burnout syndrome.

\section{$3 \quad$ Finding of the Survey}

\subsection{Sociodemographic, professional, and personal characteristics}

The present study involved 30 nurses at the Mohammed VI University Hospital (Hassan II Oncology Centre) - Oujda, Morocco. The population is made up of 13 men and 17 women. The mean age is 29 years with a standard deviation of 5,85. The youngest was aged 21 and the oldest nurse was aged 51 . Nurses are mostly single with a proportion of $63,3 \%$. More than $20 \%$ are radiology technicians, $63,3 \%$ are multipurpose nurses and the remainder have a variety of specialties. $90 \%$ of them had fewer than 10 years of professional experience. $13,3 \%$ work on-call and $26,7 \%$ work 
combine normal hours and on-call work, 50\% have normal working hours. 83,3\% of participants were not following a diet and $46,7 \%$ of them did sport regularly.

Table 1. Distribution of the population according to their socio-demographic, personal and professional characteristics

\begin{tabular}{|c|c|c|c|c|c|}
\hline \multicolumn{2}{|c|}{ Variables } & $\mathbf{N}$ & $(\%)$ & Max & Min \\
\hline \multirow{2}{*}{ Gender } & Women & 17 & 56.7 & & \\
\hline & Man & 13 & 43.3 & & \\
\hline \multicolumn{2}{|l|}{ Age } & - & - & 51 & 21 \\
\hline \multirow{3}{*}{ Marital status } & Single & 19 & 63.3 & & \\
\hline & Married & 10 & 33.3 & & \\
\hline & Divorced & 01 & 03.3 & & \\
\hline \multirow{4}{*}{ Profile } & Multi-purpose nurse & 19 & 63.3 & & \\
\hline & Radiology technician & 07 & 23.3 & & \\
\hline & Anesthesia nurse & 03 & 10.0 & & \\
\hline & Other & 01 & 03.3 & & \\
\hline \multirow{4}{*}{ Work schedule } & Normal & 15 & 50.0 & & \\
\hline & On-call & 04 & 13.3 & & \\
\hline & Normal + on-call & 08 & 26.7 & & \\
\hline & Other & 03 & 10.0 & & \\
\hline \multirow[t]{2}{*}{ On diet } & Yes & 05 & 16.7 & & \\
\hline & No & 25 & 83.3 & & \\
\hline \multirow{2}{*}{ Takes food supplements } & Yes & 05 & 16.7 & & \\
\hline & No & 25 & 83.3 & & \\
\hline \multirow{2}{*}{ Does sport } & Yes & 14 & 46.7 & & \\
\hline & No & 16 & 53.3 & & \\
\hline \multirow{2}{*}{ Cardiovascular disease } & Yes & 00 & 00.0 & & \\
\hline & No & 30 & 100.0 & & \\
\hline
\end{tabular}

More than $80 \%$ took no vitamins or food supplements and only $16,7 \%$ selfmedicated, in general for fatigue, pain, or headaches. None of the participating nurses suffered from diabetes or cardiovascular disease (see Tab. 1).

\subsection{Burnout: result}

The Copenhagen Burnout Inventory revealed that $23 \%$ of the participating nurses had a high patient-related burnout score (34\% medium, $43 \%$ low), and more than $16 \%$ had a high general burnout score (63.3\% medium, 20\% low) (see Tab. 2).

Table 2. Distribution of the population according to CBI score

\begin{tabular}{|l|c|c|}
\hline \multicolumn{1}{|c|}{ CBI } & Patient-related burnout score & General burnout score \\
\hline Low & $(\mathrm{n}=13) 43 \%$ & $(\mathrm{n}=06) 20 \%$ \\
\hline Medium & $(\mathrm{n}=10) 34 \%$ & $(\mathrm{n}=19) 63.3 \%$ \\
\hline High & $(\mathrm{n}=07) 23 \%$ & $(\mathrm{n}=05) 16.7$ \\
\hline
\end{tabular}


Figure 1 shows that $17 \%$ of nurses display a high level of burnout in both its dimensions (patient-related burnout and general burnout) and 56\% are highly susceptible to it.

Table 3. Comparative analysis between the CBI result and the sociodemographic, personal and professional characteristics

\begin{tabular}{|c|c|c|c|c|c|c|c|c|}
\hline & \multicolumn{2}{|c|}{ Low } & \multicolumn{2}{|c|}{ Medium } & \multicolumn{2}{|c|}{ High } & \multirow[b]{2}{*}{$p$} \\
\hline & & $n$ & $\%$ & $n$ & $\%$ & $n$ & $\%$ & \\
\hline \multirow{2}{*}{ Gender } & Woman & 03 & 17.65 & 10 & 58.82 & 04 & 23.53 & \multirow{2}{*}{0.31} \\
\hline & Man & 05 & 38.46 & 07 & 53.85 & 01 & 07.69 & \\
\hline \multirow{3}{*}{ Marital status } & Single & 03 & 16 & 11 & 58 & 05 & 26 & \multirow{3}{*}{0.12} \\
\hline & Married & 05 & 50 & 05 & 50 & 00 & 00 & \\
\hline & Divorced & 00 & 00 & 01 & 100 & 00 & 00 & \\
\hline \multirow[t]{3}{*}{$\begin{array}{l}\text { Number of } \\
\text { children }\end{array}$} & 0 & 05 & 20 & 15 & 60 & 05 & 20 & 0.14 \\
\hline & $<=2$ & 01 & 33 & 02 & 67 & 00 & 00 & \\
\hline & $>2$ & 02 & 100 & 00 & 00 & 00 & 00 & \\
\hline \multirow{4}{*}{ Profile } & $\begin{array}{l}\text { Multi- } \\
\text { purpose } \\
\text { nurse }\end{array}$ & 05 & 26.32 & 10 & 52.63 & 04 & 21.05 & \multirow{4}{*}{0.35} \\
\hline & \begin{tabular}{|l} 
Radiology \\
technician
\end{tabular} & 01 & 14.29 & 06 & 85.71 & 00 & 00 & \\
\hline & $\begin{array}{l}\text { Anesthesia } \\
\text { nurse }\end{array}$ & 01 & 33.33 & 01 & 33.33 & 01 & 33.33 & \\
\hline & Other & 01 & 100 & 00 & 00 & 00 & 00 & \\
\hline \multirow[t]{4}{*}{ Experience } & $<1$ year & 01 & 100 & 00 & 00 & 00 & 00 & 0.29 \\
\hline & 1-5 years & 03 & 13.04 & 15 & 65.22 & 05 & 21.74 & \\
\hline & 6-10 years & 01 & 33.33 & 02 & 66.66 & 00 & 00 & \\
\hline & $>10$ years & 03 & 100 & 00 & 00 & 00 & 00 & \\
\hline \multirow{4}{*}{$\begin{array}{l}\text { Work } \\
\text { schedule }\end{array}$} & Normal & 04 & 26.66 & 08 & 53.34 & 03 & 20 & \multirow{4}{*}{0.99} \\
\hline & On-call & 01 & 25 & 02 & 50 & 01 & 25 & \\
\hline & $\begin{array}{l}\text { Normal-On- } \\
\text { call }\end{array}$ & 02 & 25 & 05 & 62.5 & 01 & 12.5 & \\
\hline & Other & 1 & 100 & 00 & 00 & 00 & 00 & \\
\hline \multirow{2}{*}{ On diet } & No & 07 & 28 & 13 & 52 & 05 & 20 & \multirow{2}{*}{0.80} \\
\hline & Yes & 01 & 20 & 04 & 80 & 00 & 00 & \\
\hline \multirow{2}{*}{$\begin{array}{l}\text { Takes food } \\
\text { supplements }\end{array}$} & No & 08 & 32 & 12 & 48 & 05 & 20 & \multirow{2}{*}{0.08} \\
\hline & Yes & 00 & 00 & 5 & 100 & 00 & 00 & \\
\hline \multirow{2}{*}{ Does Sport } & No & 05 & 31.25 & 08 & 50 & 03 & 18.75 & \multirow{2}{*}{0.88} \\
\hline & Yes & 03 & 21.43 & 09 & 64.29 & 02 & 14.28 & \\
\hline
\end{tabular}

The analyses using the Fisher Exact Test have not revealed any significant link between the score for the Copenhagen Burnout Inventory and the other variables (sport, food supplements, diet, work schedule, years of experience, professional profile, number of children, marital status, gender) at the threshold of $(\mathrm{p}=0.05)$ (see Tab. 3). 


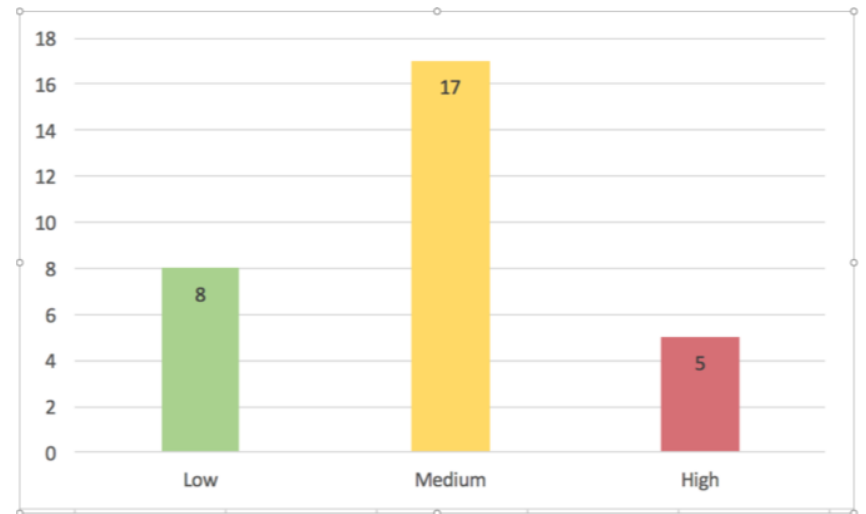

Fig. 1. Distribution of the population according to results of both dimensions of $\mathrm{CBI}$

\subsection{The practice of physical and sports activities}

The Ricci-Gagnon survey revealed that $26(87 \%)$ of participants were physically active and 2 (7\%) were inactive (see Fig. 2), which means that our population is physically active.

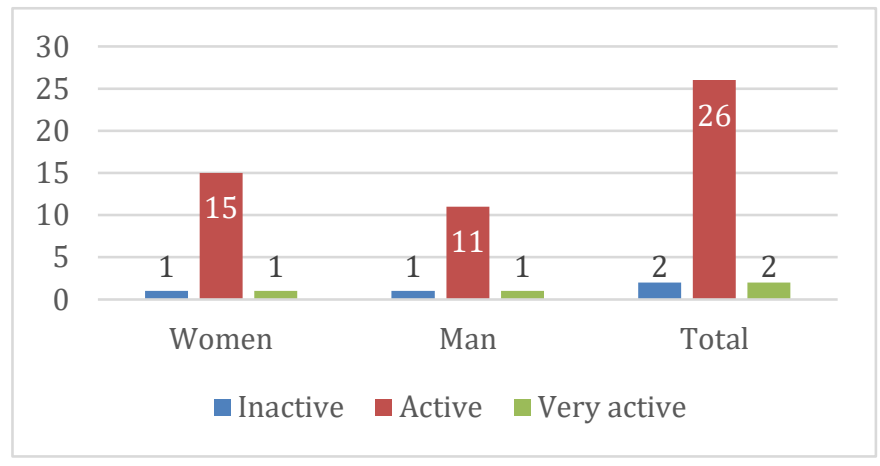

Fig. 2. Distribution of the population according to the Ricci-Gagnon questionnaire results

\subsection{Use of ICT}

This survey revealed that 25 of the participants (83\%) agreed that a platform should be set up to train, assess, and support nurses to cope with burnout. The same proportion regularly used smartphones, computers, and online training platforms to find information in daily life (see Tab. 4). 
Table 4. Use of information and communications technologies

\begin{tabular}{|l|c|c|c|}
\hline \multicolumn{1}{|c|}{ Use of ICT } & Yes & More or less & No \\
\hline $\begin{array}{l}\text { Use of ICT (smartphone, computer, online training platform) to } \\
\text { look for information }\end{array}$ & $83 \%$ & $17 \%$ & $0 \%$ \\
\hline $\begin{array}{l}\text { Opinion regarding setting up a platform for training, assessing, and } \\
\text { supporting nurses to cope with burnout }\end{array}$ & $83 \%$ & $14 \%$ & $3 \%$ \\
\hline
\end{tabular}

The training, assessing, and supporting platform will facilitate access to burnout awareness courses, it will allow individuals to assess their burnout level periodically and also to ask for the opinion of a psychologist if necessary. These processes will be carried out through an information and communication system (see Fig. 3).

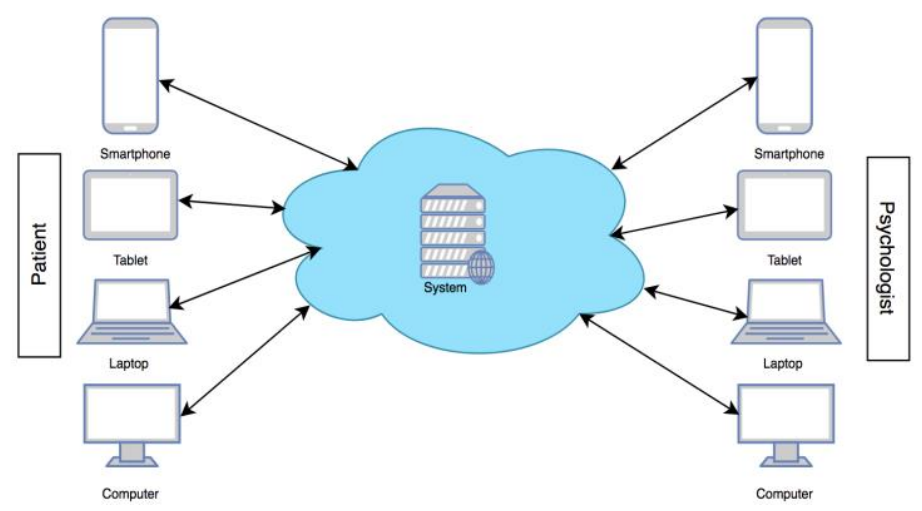

Fig. 3. Network architecture

\section{$4 \quad$ Related Works}

The findings show that $17 \%$ of nurses display a high level of burnout in both its dimensions and that more than $50 \%$ are highly susceptible to it (see Fig. 1). A predominance of the female sex can be observed, which can be explained by the fact that the nursing profession tends to be female-dominated. These figures are close to those found in the international literature [5] [15] since little data on this subject exist in Morocco. Recently, a Moroccan survey [16] carried out in the private sector showed that $17.35 \%$ of healthcare professionals suffered a high level of burnout, which shows that burnout exists in the private sector and not just in the public sector.

An analysis has been carried out of any association between the score for burnout and the sociodemographic, personal and professional variables: "gender"; "family situation"; "several children"; "professional profile"; "professional experience"; "work schedule"; "diet"; "sporting activities". Analyses using the Fisher Exact Test have not revealed any significant link between the score for burnout and the other variables at the threshold of $(p=0.05)$.

Several types of research have shown preventive, protective, and therapeutic effects of the practice of physical and sports activities on several pathologies such as 
diabetes, metabolic syndrome, cancers, stress, and depression [17] [18]. Although 28 participants $(87 \%)$ in our study were considered active, we did not find this preventive or protective effect of physical activity and sports to be stress-protective. This result confirms that of a study on burnout syndrome among paramedical health care workers in Cameroon [19].

In today's world, information and communication technologies play an important part in simplifying our personal and professional lives, in particular in the field of public health. Interactive eHealth and $\mathrm{m}$-Health services online allow individuals to consult their medical records themselves [20] using the web or mobile interfaces on a computer or smartphone. E-Health is one of the most famous digital tools of information and communication technologies and it has served vastly to public health delivery through the provision of quality health service [21], it is also facilitating immediate communication and information sharing between different health actors through dynamic social interactions via information systems [22] or the telemedicine healthcare system [23]. Such systems are set up on the internet and serve primarily to support the patient and meet his biopsychosocial needs. Therefore, the use of information and communication technologies is recommended to prevent burnout.

In this study, we noted that the majority of the nurses agreed with the idea of setting up a platform for training, assessment, and support to prevent burnout. Various studies have shown that information and communication technologies allow organizations to reduce the involvement of management [24], maximize productivity, and renew the skills of employees so that they can develop professionally and perform better [25].

\section{$5 \quad$ Conclusion and Future Work}

This research result confirmed what exists in other scientific publications; the prevalence of burnout is a reality in the health professions. It is necessary to think of setting up accompaniments strategies to sensitize nurses for primary prevention against burnout, to improve the quality of their working life.

In future work, we propose the implementation of a mobile health information system to prevent burnout and psychosocial risks, and whose principal aim is to guarantee the well-being and personal and professional development of employees, this tool will be composed of three services:

- Training is the first service that will be developed. Its main objective is to raise the awareness of burnout among healthcare professionals using constructivist pedagogical approaches and dynamic, interactive educational tools that can help to warn about and fully comprehend the seriousness of, this syndrome.

- Assessment is the service that allows the individual to determine the state of his biopsychological health by filling in a questionnaire that contains questions on physiological health and also a psychometric tool.

- Support is the third service, it allows for the permanent provision of social support by specialists in psychiatry, occupational psychology, and neuro-linguistics programming, which is directed at those with a moderate or high level of burnout. 
The prevalence of burnout is a reality in the health professions. The implementation of a mobile health information system will allow us to strengthen the support to people who suffer in their professional life and to reduce the prevalence of burnout. It is thus highly desirable to establish interactive services for training or awarenessraising, self-assessment, and support within the health professional organism to sensitize nurses for primary prevention against burnout.

\section{$6 \quad$ References}

[1] P. Lengagne. Inciter les entreprises à améliorer la santé au travail: La tarification à l'expérience dans les systèmes d'assurance des risques professionnels. Regards, vol. $\mathrm{N}^{\circ}$ 51, no 1, p. 51-61, juill. 2017, https://doi.org/10.3917/regar.051.0051

[2] HAS. Repérage et prise en charge cliniques du syndrome d'épuisement professionnel ou burnout - Manifestations cliniques et démarche diagnostique. Fiche Mémo, p. 5, mars 2017.

[3] W. B. Schaufeli and E. R. Greenglass. Introduction to special issue on burnout and health. Psychology \& Health, vol. 16, no 5, Art. no 5, Sept. 2001, https://doi.org/10. 1080/08870440108405523

[4] D. Truchot. Epuisement professionnel et burnout Concepts, modèles, interventions. Dunod, 2004.

[5] M.-A. Doppia, M. Estryn-Béhar, C. Fry, K. Guetarni, and T. Lieutaud. Enquête comparative sur le syndrome d'épuisement professionnel chez les anesthésistes réanimateurs et les autres praticiens des hôpitaux publics en France (enquête SESMAT). Annales Françaises d'Anesthésie et de Réanimation, vol. 30, no 11, p. 782-794, nov. 2011, https://doi.org/10.1016/j.annfar.2011.05.011

[6] M. Formarier. La relation de soin, concepts et finalités. Recherche en soins infirmiers, vol. 89, no 2, Art. no 2, 2007, https://doi.org/10.3917/rsi.089.0033

[7] CII. Le role des infirrmières dans l'atteinte des objectifs de développement durabe. Conseil internationnal des infirmières, 2017.

[8] E. Bourgkard, V. Demange, and C. Aubry. L'épidémiologie en santé au travail. Département Epidémiologie en entreprise, INRS, 2007.

[9] J. Ricci, and L. Gagnon. Test Ricci et Gagnon. Sport Santé Bien-Être en Bretagne, modified by F. Laureyns and JM. Séné. https://bretagne-sport-sante.fr/documentation-grandpublic

[10] M. Estryn-Béhar, B. Van der Heijden, H. Oginksa, D. Camerino, O. Le Nézet, P. M. Conway, C. Fry, and H-M. Hasselhorn. The Impact of Social Work Environment, Teamwork Characteristics, Burnout, and Personal Factors Upon Intent to Leave Among European Nurses. Medical Care, vol. 45, no 10, Art. no 10, Oct. 2007, https://doi.org/10. 1097/mlr.0b013e31806728d8

[11] M. Estryn-Behar, M.-H. Braudo, C. Fry, and K. Guetarni. Enquête comparative sur le syndrome d'épuisement professionnel chez les psychiatres et les autres spécialistes des hôpitaux publics en France (enquête SESMAT). L'information psychiatrique, vol. 87, no 2, Art. no 2, 2011, https://doi.org/10.3917/inpsy.8702.0095

[12] M. Borritz, R. Rugulies, J. B. Bjorner, E. Villadsen, O. A. Mikkelsen, and T. S. Kristensen. Burnout among employees in human service work: design and baseline findings of the PUMA study. Scandinavian Journal of Public Health, vol. 34, no 1, Art. no 1, Jan. 2006, https://doi.org/10.1080/14034940510032275 
[13] V. Langevin, S. Boini, M. François, and A. Riou. Copenhagen Burnout Inventory (CBI) (Inventaire de burnout de Copenhague). Références en santé au travail - Risques psychosociaux: outils d évaluation - FRPS 38, 2014.

[14] T. S. Kristensen, M. Borritz, E. Villadsen, and K. B. Christensen. The Copenhagen Burnout Inventory: A new tool for the assessment of burnout. Work \& Stress, vol. 19, no 3, p. 192-207, Jul. 2005, https://doi.org/10.1080/02678370500297720

[15] M. Estryn-Behar, O. le Nezet, N. Bonnet, and P. Gardeur. Comportements de santé du personnel soignant. La Presse Médicale, vol. 35, no 10, p. 1435-1446, oct. 2006, DOI: https://doi.org/10.1016/s0755-4982(06)74832-1

[16] F. Asbayo and M. Hajaoui. L'épuisement professionnel des infirmiers: secteur privé marocain. Archives des Maladies Professionnelles et de l'Environnement, vol. 79, no 3, p. 442, mai 2018, https://doi.org/10.1016/j.admp.2018.03.526

[17] L. Bherer, K. I. Erickson, and T. Liu-Ambrose. A review of the effects of physical activity and exercise on cognitive and brain functions in older adults. J Aging Res, vol. 2013, p. 657508, 2013, https://doi.org/10.1155/2013/197326

[18] E. B. Larson, L. Wang, J. D. Bowen, W. C. McCormick, L. Teri, P. Crane and W. Kukull. Exercise Is Associated with Reduced Risk for Incident Dementia among Persons 65 Years of Age and Older. Ann Intern Med, vol. 144, no 2, p. 73-81, janv. 2006, DOI: https://doi.org/10.7326/0003-4819-144-2-200601170-00004

[19] P. T. Moueleu Ngalagou, P. B. Assomo Ndemba, L. J. Owona Manga, Y. Bandga Ekanga, W. R. Guessogo, C. N. Ayina Ayina, and S. H Mandengue. Syndrome du burnout chez le personnel soignant paramédical au Cameroun: impact des activités physiques et sportives et des loisirs. Archives des Maladies Professionnelles et de l'Environnement, vol. 79, no 1, p. 55-63, févr. 2018, https://doi.org/10.1016/j.admp.2017.10.006

[20] L. Gossec, A. Cantagrel, M. Soubrier, J-M. Berthelot, J-M. Joubert, B. Combe, W. Czarlewski, D. Wendling, E. Dernis, L. Grange, C. Beauvais, A. Perdriger, H. Nataf, M. Dougados, and H. Servy. Sanoïaß, plateforme e-santé interactive d'auto-évaluation dans la polyarthrite rhumatoïde. Essai comparatif randomisé de 12 mois sur 320 patients. Revue du Rhumatisme, vol. 86, no 1, Art. no 1, Jan. 2019, https://doi.org/10.1016/ j.rhum.2018.08.002

[21] A. Omotosho, P. Ayegba, J. Emuoyibofarhe, and C. Meinel. Current State of ICT in Healthcare Delivery in Developing Countries. International Journal of Online and Biomedical Engineering (iJOE), vol. 15, no 08, p. 91, Mai 2019, https://doi.org/10.3991/ ijoe.v15i08.10294

[22] F. Sanfilippo and C. Pacchierotti. A Wearable Haptic System for the Health Monitoring of Elderly People in Smart Cities. International Journal of Online and Biomedical Engineering (iJOE), no 08, p. 52, août 2018, https://doi.org/10.3991/ijoe.v14i08.8571

[23] M. M. Abdellatif and W. Mohamed. Telemedicine: An IoT based Remote Healthcare System. International Journal of Online and Biomedical Engineering (iJOE), vol. 16, no 06, p. 72, mai 2020, https://doi.org/10.3991/ijoe.v16i06.13651

[24] J. Medzo-M'engone, M.-É. Bobillier-Chaumon, and M. Préau. Changements technologiques, TIC et santé psychologique au travail: une revue de la littérature. Psychologie Française, p. S0033298418300189, août 2018, https://doi.org/10.1016/j.psfr.2018. 03.002

[25] Y. Clot and P. Béguin. L'action située dans le développement de l'activité. Activites, vol. 01, no 2, oct. 2004, https://doi.org/10.4000/activites.1237 


\section{$7 \quad$ Authors}

Mohammed Amine Lafraxo is a Ph.D. student in education and Health informatics, at the Laboratory of Biology and Health at the Faculty of Sciences, Ibn Tofail University. He has a Master's degree in educational technology from the "École Normale Supérieure, ENS" of Martil, Morocco in 2016, and two bachelor's degrees in computer engineering and medical informatics. His current research focuses on Elearning, Software Engineering, Big Data, Biometry, Epidemiology, Public Health, Stress, and Burnout Syndrome. Email: 1afraxo.ma@gmail.com

Mohammed Ouadoud is a Muslim man from Morocco. He is a Ph.D. Research Scholar in Computer sciences, at the Laboratory of the Information System and Software Engineering (SIGL) at National School of Applied Sciences, Abdelmalek Essaâdi University, Tetouan, Morocco. In 2018, He completed his Ph.D. thesis in computer science at the faculty of science of Tetouan, Morocco. His dissertation research focuses on Modeling and Prototyping a Learning Management System Based on the IMD-LD, the NoSQL, and the Hybridization between Learning Theories. He has a Master's degree in Instructional design multimedia engineering from the École Normale Supérieure of Martil, Morocco in 2013. His current research focuses on Elearning, Software Engineering, Geomatics, Public Health, and Bigdata. He is a reviewer in several international journals. Email: mohammed.ouadoud@gmail.com

Youssef El Madhi is a Ph.D. Research Scholar in Biology and Health. He is with the Research Laboratory for Education, Environment and Health, CRMEF Rabat, Morocco. Email: youssmad@yahoo.fr

Abdelmajid Soulaymani is a Professor of Higher Education in Genetics and Biostatistics since 1986 - Vice Dean of the Faculty of Science at Ibn Tofail University, Morocco. Director of the Center for Doctoral Studies in Science and Technology from 2014 to 2019 - Director of the Laboratory of Genetics and Biometrics. Email: soulaymani@uit.ac.ma

Article submitted 2021-01-08. Resubmitted 2021-02-06. Final acceptance 2021-02-07. Final version published as submitted by the authors. 